\title{
Group Composition and Its Impact on Effective Group Treatment of HIV and AIDS Patients
}

\author{
Margaret J. Siebert ${ }^{1}$ and William I. Dorfman ${ }^{1}$
}

This paper reviews the literature on group therapy in the treatment of people with the Human Immunodeficiency Virus (HIV) and people with Acquired Immune Deficiency Syndrome (AIDS). Specifically, it examines the effect of group composition on the curative factors of group therapy. The variables of group composition explored are stage of illness, risk group for contracting HIV, and gender. This paper suggests that support groups that are homogeneous for stage of illness, risk behaviors, and gender provide members with the greatest benefits through facilitating the curative factors of group therapy: instillation of hope, universality, and group cohesion.

KEY WORDS: groups; support; HIV.

\section{INTRODUCTION}

Studies have found that people who test positive for the Human Immunodeficiency Virus (HIV) are likely to react with an increase in feelings of anxiety and depression (Tross and Hirsch, 1988). Many people have looked to the mental health system for help in dealing with their reactions to their HIV-positive status. Several studies have revealed that people who test positive for HIV, and people with Acquired Immune Deficiency Syndrome (AIDS) have an interest in support groups and psychotherapy for help in coping with their diagnosis and the sequelae of AIDS (Child and Getzel, 1989; Donlou and Wolcott, 1985, as cited in Fawzy et al., 1991; Wolcott et al., 1986).

Group therapy is the approach utilized most frequently by mental health workers to assist people in dealing with the emotional consequences

${ }^{1}$ Nova Southeastern University, Fort Lauderdale, Florida 33314. 
of AIDS (Sageman, 1989). In the AIDS literature, the value of group intervention is particularly emphasized. Groups have been recognized as a valuable and a readily available source of support for People With Aids (PWAs) (Getzel, 1991). In New York City, the Gay Men's Health Crisis (GMHC) reports that $30 \%$ of its clients request group services, and more than 60 different groups meet weekly (Katoff and Dunne, 1988). Price et al. (1986) believe group therapy to be the treatment of choice for most people with AIDS, and this opinion is shared by others (Beckett and Rutan, 1990; Child and Getzel, 1989; Spector and Conklin, 1987; Thompson and Wardrope, 1988; Tunnell, 1991). A review of the literature on group therapy in the treatment of PWAs and those diagnosed with HIV reveals that the majority of papers are anecdotal. They offer clinical vignettes of authors' experiences and impressions gathered from conducting HIV and AIDS support groups. Only three empirical studies were found that explore the efficacy of group intervention with this population. Of these studies, one explores the efficacy of structured group intervention with PWAs (Fawzy et al., 1989), and another explores the efficacy of structured group intervention with people diagnosed HIV-positive, but who are asymptomatic (Levine et al., 1991). While both studies report decreases in group participants' psychological distress, no statistical measures were used to support either study's findings. The third study employed questionnaires to evaluate the effectiveness of a psychoeducational support group for PWAs, HIV-positive symptomatic, asymptomatic, and HIV negative members (Hedge and Glover, 1990). This study reported that the group was positively evaluated by the majority of group members.

In reviewing the literature of group psychotherapy, group composition emerges as an issue relevant to the group treatment of HIV/PWA's. Specifically, three variables of group composition (stage of illness, risk group, and gender) have been identified as being important in working with this population, whether in structured, educational groups, or in traditional therapy. A controversy surrounds the fact that some clinicians believe that group members should be homogeneous on one or more of these variables, while other clinicians assert that heterogeneity with respect to these variables offers group members greater benefits. There is little in the current literature, however, that would assist the practicing clinician in forming the HIV group, and no accepted theoretical model to guide him or her in deciding on group composition. The purpose of this paper is: (1) to explore the arguments proferred in the literature for and against group homogeneity on each of these three factors of group composition; and (2) to present a theoretical framework to guide the practitioner in deciding on the most effective composition of groups for PWA's and those infected with HIV. 
Yalom (1985) presents a theory of group psychotherapy that identifies 12 mechanisms and conditions for change which he proposes are the curative factors of group psychotherapy, including altruism, group cohesiveness, universality, interpersonal learning-input and output, guidance, catharsis, identification, family re-enactment, self-understanding, instillation of hope and existential factors. Of these curative factors, group cohesion, universality, and instillation of hope will be utilized as the most relevant and sensitive to the issue of HIV or AIDS group composition. Yalom theorizes that group cohesiveness results from the group member's relationship to other members and to the therapist, and can be understood through "the attractiveness of a group for its members" (Yalom, 1985, p. 49). Group cohesion may be indicated by better attendance, less conflict, immediate support, increased self-disclosure, and group members' relief of symptoms. Yalom (1985) suggests that the group experience provides individuals with an opportunity to feel connected with other people, and provides them with a sense of "all being in the same boat." This curative factor of universality disconfirms group members' sense of uniqueness and isolation. The third relevant curative factor, instillation of hope, can be observed, according to Yalom (1985), when members of a group feel hopeful when they see another member improve. If a member who has similar problems begins to cope more effectively with his/her problems, then other members are likely to believe that they too may improve.

In this paper we review the relevant literature in terms of three dimensions of group composition (stage of illness, risk factors, and gender) and assess the impact of each on members according to three of Yalom's critical curative factors: instillation of hope, universality, and group cohesion.

\section{STAGE OF ILLNESS}

A factor of group composition that is controversial in the HIV/AIDS literature is the issue of mixing members who are at various stages of the spectrum of HIV/AIDS illness: that is, when they are considered to be HIV positive and asymptomatic, symptomatic (shingles, thrush), or diagnosed with AIDS (i.e., presence of Kaposi's Sarcoma, Pneumocystis Carinii Pneumonia, or T-cell count less than 200 [Davis, 1991]).

A review of the literature reveals that there is a lack of agreement over whether support groups should mix symptomatic and asymptomatic members. Of the articles reviewed, 14 (66\%) described groups homogeneously composed for stage of illness: that is, groups composed of members who were either all symptomatic or asymptomatic (Beckett and Rutan, 
1990; Beckham, 1988; Brauer, 1990; Child and Getzel, 1989; Christ et al., 1986; Chung and Magraw, 1992; Coleman and Harris, 1989; Fawzy et al., 1989; Gambe and Getzel, 1989; Getzel and Mahoney, 1990; Grant, 1988; Mancoske and Lindhorst, 1991; Spector and Conklin, 1987; Zakrzewski, 1991). Conversely, a third of the studies identified described groups that were heterogeneous for stage of illness. Although most reported cases consist of members who share stage of illness characteristics, there is often no clear rationale offered for patient selection. For example, Wolcott et al. (1985) believe that groups homogeneous for risk group, disease category, and illness stage may be most successful. They do not, however, offer any data or rationale to support this belief.

The curative factors of instillation of hope, universality, and group cohesion may offer a set of criteria on which to more adequately evaluate the interaction of group composition and stage of illness.

\section{Instillation of Hope}

One argument in favor of homogeneously composed support groups for stage of illness centers around the observation that asymptomatic members frequently are disturbed by seeing symptomatic members. Nichols (1986) noted that attending a support group can be traumatic for newly diagnosed patients as new members hear detailed accounts of the disease. Other authors supported this observation, noting that the group can be frightening (Beckett and Rutan, 1990; Mancoske and Lindhorst, 1991; Morin et al., 1984; Sageman, 1989; Tunnell, 1991), and anxiety provoking (Katoff and Dune, 1988). Weiss (1988) observed that even those people who attempt to maintain hope and treat AIDS as a challenge may find the heterogeneous group causing distress by reminding them of their vulnerability and eventual death.

A few authors attempt to view groups with members at mixed stages of illness in a positive light (Beckett and Rutan, 1990; Katoff and Dunne, 1988; Nichols, 1983). Beckett and Rutan (1990) wrote that, although the group may be terrifying, it may also be reassuring, because many group members are well for long periods of time. Nichols (1983) suggested that mixed groups allowed for a more optimistic atmosphere, and that it better represented the uncertainties that accompany having AIDS. Some authors felt that heterogeneous groups would force group members to deal with their fears immediately and directly (Katoff and Dunne, 1988; Nichols, 1983).

With hopelessness that accompanies a terminal illness, the factor of instillation of hope obviously becomes critical. For asymptomatic members, 
being in groups with physically deteriorated members can further their sense of despair rather than offering hopefulness regarding the future. There appears to be general agreement in the literature that HIV/AIDS support groups mixed for stage of illness can be a frightening, anxiety provoking and an overwhelming experience for some members, ultimately not conducive to instilling hope in its members.

\section{Universality}

All members of a support group for people with HIV or PWAs are "in the same boat," in that they are all infected with HIV. However, there is some question of just how similar this population is. For example, Thompson and Wardrope (1988) found that people at different stages of illness have different needs. Grant and Anns (1988) found that people's needs were different, depending upon their stage in the reactive process following diagnosis. They found that short-term reactions followed the diagnosis (shock, anger, anxiety, sexual dysfunction, depression), then long-term reactions followed (existential, lost relationships). Gambe and Getzel (1989) also found that there is an active crisis and shock following diagnosis.

Coleman and Harris (1989) noted differences, but were more specific as to the time frame in which the differences were observed. They found clear differences in the psychosocial needs of individuals who had known about their HIV-positive status under three months, and those who had known for a longer period of time. Coleman and Harris also identified an initial crisis period, followed by an adjustment period in which people had learned how to live with HIV. In a correlational study by Kurdek and Siesky (1990), asymptomatic, HIV-positive men had a worse psychological adjustment profile, and employed less effective coping strategies than HIV-positive men with symptoms. Grant (1988) reported that the experience of being diagnosed as HIV-positive with symptoms is different from and can be more severe than AIDS (Temoshok et al., 1986, as cited in Grant, 1988). This suggests that perhaps there are three different populations, each with their own psychological reactions and needs, at different stages of illness (diagnosis/asymptomatic; symptomatic; AIDS).

Some research reported offering different types of groups for HIV infected people at different stages of illness (Christ et al., 1986; Coleman and Harris, 1989; Gambe and Getzel, 1989), or at specific points in the reactive process (Brauer, 1990; Levy et al., 1990).

On one side, arguing for heterogeneously composed groups on stage of illness, Levy et al. (1990) noted that in heterogeneous groups members 
are at different stages of coping, and consequently have different contributions to make to the group. They believe that heterogeneous groups positively contribute to the therapeutic factors of group therapy. Hedge and Glover (1990) found that mixed groups allowed members to share experiences from a variety of perspectives, and gave insights into how some members coped with issues that for other members may have been frightening to confront. Group members coped with both sickness and good health, and provided a variety of role models. Beckett and Rutan (1990) found that homogeneous groups can also offer group members a variety of coping responses. Homogeneous group members may initially focus on their commonality, but in time they can identify their varied responses to the common dilemma of their shared diagnosis.

In summary, the literature reveals that the population of HIV infected people seems to be composed of several subgroups which can be identified by their position on the continuum of HIV health or illness. It would seem that for groups to benefit from the curative factor of universality, group members should be from the same subgroup. Then, members would have greater commonality and benefit more from the effect of universality than if they were in mixed groups.

\section{Group Cohesion}

As noted previously, cohesive groups are better attended and have less premature termination by group members. Beckham (1988) pointed out that for people with HIV or PWAs, who are already dealing with enormous losses, it is important to provide a group format that does not add to their losses. Cohesive groups may be less likely to add to group members' losses, since such groups would have fewer group members prematurely terminate treatment. Hockings (1989) observed that in support services mixed for stage of illness, $95 \%$ of PWAs committed to long-term support services. In contrast, $70 \%$ of HIV-positive members came for only one or two sessions, and did not return. Mulleady, Riccio, and Hogarth (1989) also found that asymptomatic members were reluctant to continue attendance in their mixed group. And, Field and Shore (1992) reported that five of seven asymptomatic HIV-positive members dropped out of their heterogeneously composed group. Thus, it seems that groups which are heterogeneous for stage of illness may be less cohesive, and they may further add to all members' feeling of loss. Premature termination can be experienced as a loss for the asymptomatic members who leaves the group, and for group members who lose the new members. Clearly, premature termination interferes with group cohesion. 
Spector and Conklin (1987) believe that healthier members dropped out of mixed groups because the confrontation with physically-debilitated members left healthier members with intolerable fears. Spector and Conklin observed another problem in heterogeneous HIV/AIDS support groups that interferes with group cohesion. They conducted a support group in which the membership was mixed for stage of illness, and found that after the first eight weeks of group therapy, divisions appeared between the healthy and physically ill members. They recommend that HIV or AIDS support groups should be composed of members homogeneous for stage of illness. Beckett and Rutan (1990) also found powerful reactions of asymptomatic members to physically ill members, but they also noted that ill members may have difficulty relating to well members, perhaps finding their concerns trivial. Tunnell (1991) noted that group members who are more ill may not be empathic to the healthier members' concerns, and vice versa. Further, on-going support groups can become disruptive when newlydiagnosed members continually are integrated and require answers to many basic informational questions (Coleman and Harris, 1989; Katoff and Dunne, 1988), and have different emotional issues (Coleman and Harris, 1989). In heterogeneous groups, the difficulty group members may have in relating to each others' health or illness seems to threaten the development of a therapeutic alliance (Beckett and Rutan, 1990), and ultimately impedes group cohesion.

Overall, it appears that groups which are homogeneous for stage of illness offer members greater benefits when evaluated in terms of the curative factors of instillation of hope, universality, and group cohesion.

\section{RISK GROUPS}

It is acknowledged that what places a person at risk for HIV infection are specific, risk behaviors (i.e., unprotected sex with a person also at risk for HIV infection, sharing needles and "works" with other IVDUs) and not the fact that a person is gay or uses drugs. However, for the sake of brevity, the term "risk group" will be used in place of noting all of the behaviors in which people may engage in order to put themselves at risk for contracting HIV. In the beginning of the AIDS epidemic, gay and bisexual men were the first to be stricken by the disease, and therefore the first group of people who presented to the mental health community for help in coping with the illness. Much of the work that has been written about group therapy with HIV-positive people and PWAs is based on work with gay men (Cochran and Mays, 1991; Coates et al., 1987). Although the epidemic has spread to all segments of the population, several groups of 
people suffer a much greater rate of infection. Due to the routes of transmission for HIV, intravenous drug users (IVDUs), sexual partners of IVDUs, and infants born to IVDU parents are at a greater risk for having been infected with the virus which causes AIDS (Coates et al., 1987; Knapp and Vande Creek, 1990).

As the virus spread to the IVDU population, professionals continued to write about the use of group therapy in the treatment of PWAs and people infected with HIV, but little attention was given to the effects of mixing people with different risk behaviors within the same group. In fact, many articles omit details of group composition, that is, whether groups consist of gay men, IVDUs, heterosexuals, or hemophiliacs (Hockings, 1989; Katoff and Dunne, 1988; Levy et al., 1990; Nichols, 1983; Simerly and Karakashian, 1989; Tunnell, 1991). Close to $70 \%$ of the literature which reported group composition described groups which were homogeneous for risk group, with a relatively small proportion (19\%) reporting groups heterogeneous for risk group.

In exploring the effects of mixing the composition of groups to include gay men and IVDUs infected with HIV, the curative factors of universality and group cohesion seem most relevant, while instillation of hope is unlikely to be impacted significantly by risk group.

\section{Universality}

The fact that HIV primarily infects people in minority groups who are likely to already feel a sense of isolation and stigmatization from the larger society (Grant, 1988), suggests that the experience of universality and belonging is critical. All support groups for people infected with HIV or PWAs provide members with the opportunity to recognize their shared experience of living with the virus. Groups can normalize group members' emotional reactions to their diagnosis (Getzel, 1991) and help people overcome the social isolation which typically follows disclosure of their HIV-positive status (Getzel and Mahoney, 1990; Grant, 1988).

Support groups for people infected with HIV or PWAs are homogeneous, in that all members have HIV. Some authors believe that this shared medical diagnosis is sufficient for individuals to benefit from support groups, even when group composition is mixed, consisting of gay men and IVDUs. Although the authors do not specifically cite the curative factor of universality in their argument, they do seem to describe the phenomena in their observations. Mancoske and Lindhorst (1991) and others (Brauer, 1990; Child and Getzel, 1989; Getzel and Mahoney, 1990) found that diversity of group members was overcome by their common diagnosis. Brauer 
(1990) observed that the common circumstance of being HIV-positive created a bonding experience in which group members found solace in being with others who share the same medical condition. Nichols (1984) found that by mixing group composition for risk group, members discover and revise false preconceptions about one other's risk group.

Conversely, other authors argue that groups composed of members who share specific risk factors as well as HIV-positive status are more beneficial. Again, authors do not typically identify the curative factor of universality in their argument, however, they do allude to it. Zakrzewski (1991), for example, found that AIDS support groups comprised of both gays and IVDUs were counterproductive to the aims of mutual support and aid. Disparity of lifestyles was found to create barriers, which was likely to further group members' sense of isolation. Thus, the sense of being connected resulting from the curative factor of universality seemed to be diluted, if not lost, in Zakrzewski's (1991) heterogeneously composed HIV support groups.

The observation that members of heterogeneously composed HIV groups lack a sense of identification with each other is supported through other authors' experiences. Bing and Soto (1991) noted that heterosexual men may find that if they join a support group, they may be the only heterosexual man or IVDU. Nichols (1983), in an article which argued in support of mixing of group members from different risk groups, found that some IVDUs would claim to be bisexual in order to feel more comfortable in the mostly homosexual support groups. This type of group experience seems to only exacerbate their sense of isolation and alienation (Bing and Soto, 1991; Green, 1989; Hoffman, 1991). This fact could be countered by participation in support groups composed exclusively of members who share specific risk behaviors. Zakrzewski (1991) argued for IVDUs to have homogeneous groups because, unlike the gay community, they have a poor sense of community, and as a result, feel more disenfranchised and isolated. For the same reason, Mulleady et al. (1989) formed groups for HIV-positive drug users and ex-users, and they believed that heterosexuals who contracted the virus through needle sharing felt unsupported by services which focused on the homosexual community.

Not only do IVDUs and gays seem to have difficulty feeling connected to each other, in addition, some authors describe conflicts between the two groups. Thompson and Wardrope (1988) described their experience conducting HIV/AIDS support groups with a prison population. They observed prejudicial conflicts, tension, and animosity between homosexual and IVDU group members. Child and Getzel (1989) also found a tendency for a rivalry between gay and IVDU members in their outpatient support group. Ross and Rosser (1988) went on the note that some groups of in- 
dividuals may have revengeful feelings towards other groups who are perceived as transmitting the disease. This anger and displacement is likely to interfere with heterogeneous HIV/AIDS support groups' ability to benefit from the curative factor of universality.

In summary, it seems that although some authors found that the commonality of an HIV-positive or AIDS diagnosis was sufficient for a successful group experience, the curative factor of universality may be diluted in groups composed of both IVDUs and gays.

\section{Group Cohesion}

Levy et al. (1990) found that IVDUs included in mixed groups seemed to have dropped out of the group prematurely. As indicated earlier, Yalom (1985) theorizes that cohesive groups consist of members who demonstrate good attendance and have less premature termination. Levy's finding, on the other hand, suggests that some mixed groups may not be cohesive. A review of the literature on group treatment with drug addicts supports Levy's finding. Flanzer and April (1977) reviewed the literature on group therapy for drug addicts and found that mixing drug addicts and non-addicts in groups was contraindicated. Drug addicts have been found to be unable to participate in the primary task of group treatment (Flanzer and April, 1977).

Another manifestation of group cohesion identified by Yalom (1985) is self-disclosure. Cohesive therapy groups are more accepting of one another, and members offer more self-disclosing statements. Although the issue of self-disclosure has not been identified in the literature on HIV/AIDS support groups, the literature on group therapy with gay men suggests that this may be a silent problem. A review of literature on group therapy with gay men offers some insights into how homogeneous or heterogeneous HIV/AIDS support groups may affect gay members. Studies show that homosexuals in mixed groups, composed of heterosexuals and homosexuals, often attempt to hide their sexual orientation (Schwartz and Hartstein, 1986), while in homogeneous groups, gays are more open to explore their sexuality (Schwartz and Hartstein, 1986), and to verbalize their problems more freely (Bieber, 1974). Generalizing these findings to groups consisting of infected gays and IVDUs, we may suspect that heterogeneous grouping on risk factors is likely to impede gay members self-disclosure regarding their sexuality. If this is the case, then mixed groups may be less cohesive than homogeneous groups.

Several authors agree that homogeneous groups are more cohesive. For example, Tunnell (1991) believes that group cohesiveness is maximized, 
and groups are generally more productive if separate therapy groups are established for each risk group. However, Tunnell offers no rationale to support this opinion. Beckett and Rutan (1990), on the other hand, offer observations in support of this argument. Beckett and Rutan note that group members expect others to know and understand important aspects of their life situation and this can be better met in homogeneously composed groups. In homogeneous groups, the unspeakable can be spoken more readily, and with facilitation of trust, difficult material is revealed sooner than in heterogeneous groups. Beckett and Rutan believe that all of these factors serve to facilitate the building of group cohesiveness. They add that given the limited life expectancy of individuals diagnosed HIVpositive, the acceleration of group cohesiveness is important in working with this population.

Overall, it seems that group leaders have found that homogeneously composed HIV/AIDS groups may be more cohesive than heterogeneously composed groups. The curative factors of universality and group cohesion appear to offer group members greater benefits if the groups are homogeneous for risk group.

\section{GENDER}

The issue of gender and group composition has not been addressed directly in the HIV/AIDS literature. We will extrapolate from the available literature on HIV/AIDS group therapy to examine the specific effects of gender on group effectiveness.

The National Institutes of Health (1993) reported that the number of women diagnosed with AIDS jumped 50\% between 1989 and 1991, and predicts that AIDS will soon become the second leading cause of death among women aged 25 to 34 , as it is among men of that age group. In New York City, AIDS is already the leading cause of death for African American women of childbearing age (NIH, 1993). As of September 1993, women accounted for $12 \%$ of the cumulative AIDS cases (CDC, 1993). As the rate of HIV infection for women increases, it has become necessary to examine the effects of introducing women into existing support groups for HIV infected men. Of the articles reviewed, 52\% reported homogeneous (mostly male) group composition on the dimension of gender (Beckham, 1988; Brauer, 1990; Christ et al., 1986; Chung and Magraw, 1992; Coleman and Harris, 1989; Fawzy et al., 1989; Gambe and Getzel, 1989; Getzel and Mahony, 1990; Grant, 1988; Hedge and Glover, 1990; Spector and Conklin, 1987), while only two papers describe heterogeneous composition (Grief and Price, 1988; Mulleady et al., 1989). One particularly striking issue is 
that four groups reported included one or two women members in predominantly male groups (Beckett and Rutan, 1990; Field and Shore, 1992; Levine et al., 1991; Thompson and Wardrope, 1988). Yalom (1985) strongly discourages leaders from selecting patients who may be group isolates, as this composition repeats, rather than amends, the sense of isolation for which members seek group support in the first place. His theory suggests that these women who were placed in the predominately male groups may have felt further isolated, rather than understood and supported by the group experience.

The curative factors most likely to be affected by the gender of group members are universality and group cohesiveness.

\section{Universality}

Two points need to be explored on the topic of universality and gender. The first is that women with HIV are perhaps the most isolated, least supported, and least cohesive group affected by the illness (Nichols, 1989). Because of the relatively smaller number of women infected and the diversity of ways women can become infected, women often find themselves alone and feeling stigmatized. Chung and Magraw (1992) reported that women hope that by joining groups they will find others identical to themselves, because women with HIV rarely know other HIV infected women. St. John (1992) describes her work using body movement exercises with HIV-positive women. She found that when the women assembled, there was a sense of relief at being together in one place as HIV-positive women. The isolation which these women experience reportedly has been broken by the experience of being with other HIV-infected women.

The second point is that many issues men and women with HIV face are very different suggesting that they are not actually "in the same boat." For example, gynecological symptoms are often the first signs of HIV infection in women (Smeltzer and Whipple, 1991). Further, the standard of care in the epidemic is based on drug trials with men infected with HIV. Women are often categorically excluded from trials, reportedly because of the unknown effects of the new drugs on women's reproductive capacities (Hernandez, 1990, as cited in St. John, 1992; Smeltzer and Whipple, 1991). Thus, even though women are known to present with different medical complications resulting from HIV infection, the standard of care continues to be based on HIV infection in men. Not surprising, then, is the observation that some women have had to inform their physicians of the gynecological manifestations common to women with HIV (Chung and Magraw, 1992). Therefore, one benefit of HIV/AIDS support groups 
homogeneous for gender is that women can become aware and informed of HIV-related complications and interventions specific to women. Women would then have the opportunity to learn from other women who are truly "in the same boat."

There are other issues specific to HIV-infected women that are less likely to be of concern for men with HIV. Most women with HIV are of childbearing age (Smeltzer and Whipple, 1991) and, as a result, face issues that may arise from pregnancy. HIV-positive women who are pregnant risk transmitting the virus to their babies (Green, 1989; Smeltzer and Whipple, 1991), and a pregnancy may negatively influence the mother's health, the course of treatment, and the course of the illness (Green, 1989; Smeltzer and Whipple, 1991). Also, women are typically the primary source of support for young children (Hoffman, 1991), and many women place greater emphasis on caring for others over caring for themselves (Chung and $\mathrm{Ma}$ graw, 1992). Some women find that their social roles as wives and mothers are changed or lost as a result of their infection (Chung and Magraw, 1992). They may find that people view them as promiscuous and dangerous (Chung and Magraw, 1992; Smeltzer and Whipple, 1991), and they are likely to feel stigmatized and ashamed (Wiener, 1991). As these issues are specific to women, it is likely that they would best be addressed in a group comprised of women. In women's groups, the curative factor of universality can offer these women support and understanding as they go through the shared experience of being women infected with HIV.

Overall, these differences suggest that gender is likely to profoundly shape the experience of HIV and AIDS. Women's greater sense of isolation, unique clinical manifestations of HIV, and their gender specific issues are likely to best be treated in a support group homogeneous for gender. And, for women the curative factor of universality may be facilitated in groups homogeneous for gender.

\section{Group Cohesion}

As described above, attendance can be a manifestation of group cohesion. Two articles specifically address the attendance of female members in support groups for HIV-positive members, mixed for gender. Mulleady et al. (1989) conducted a group in which $2 / 3$ of group members were male, and one-third were female. Females attended less often than males. Field and Shore (1992) described their group as heterogeneous for stage of illness, risk group, and gender. Their group consisted of two female members, who both terminated because they were uncomfortable in a group composed mostly of men. As indicated previously, the women's poorer 
attendance and premature termination may be due to a lack of group cohesion in these groups which were heterogeneous for gender.

An argument in favor of mixed gender group composition comes from a study in the group therapy literature. Taylor and Strassberg (1986) explored the effects of sex composition on cohesiveness in a personal growth group. They found that an all women's group had significantly higher group cohesiveness then an all men's group. However, group cohesiveness of a mixed gender group resembled the cohesion of the women's group. That is, the mixed group reported similar levels of group cohesion as the women's group, and had a significantly greater level of cohesion than the men's group. If Taylor and Strassberg's study can be generalized to the population infected with HIV, then it would suggest that mixed gender groups may be more beneficial for men. Males may experience and benefit more from the curative factor of group cohesion in HIV/AIDS groups mixed for gender.

In summary, the curative factor of universality seems to be more helpful for women if HIV/AIDS groups are homogeneous for gender. And, the poorer attendance of women in mixed groups suggests that HIV/AIDS groups which are homogeneous for gender may offer women greater benefits from the curative factor of group cohesion. However, generalizing from literature on personal growth groups, the opposite may be true for men.

\section{SUMMARY AND CONCLUSIONS}

It is clear that there is a need for mental health services to respond to the HIV/AIDS epidemic, and that group therapy has been one way in which mental health professionals have responded. This paper explores the issue of group composition and how it interacts with the curative factors of group therapy: instillation of hope, universality, and group cohesion. After reviewing the literature, three points become clear. First, homogeneous HIV support groups are likely to develop group cohesion faster and stronger than heterogeneous groups (Rosenberg, 1984; Yalom, 1985). Second, the majority of HIV or AIDS support groups in the literature are composed of members who are homogeneous for at least one of the three variables under investigation in this paper: risk group, stage of illness, or gender. And third, although empirical studies attempt to explore the efficacy of group therapy, and the benefits of mixing members from the different stages of HIV illness, the findings are inconclusive.

Most of the articles on group therapy with this population are descriptive, anecdotal accounts of the authors' experiences. After reviewing the literature, it is apparent that support groups that are homogeneous for 
stage of illness, risk behaviors, and gender provide members with the greatest benefits by facilitating the critical curative factors in group therapy.

Arguments for heterogeneous membership seem to center around the belief that individual differences can be overcome by the commonality of sharing the same HIV-positive status and medical prognosis (Brauer, 1990; Child and Getzel, 1989; Duhatschek-Krause, 1989; Hedge and Glover, 1990; Spector and Conklin, 1987). This is likely to be true, but it seems that if groups are designed to be homogeneous for stage of illness, risk group, and gender, then there would be fewer differences that must be overcome, and cohesion can develop more rapidly. Due to the limited life expectancy of this population, rapid development of group cohesion may be important. If group cohesion can be achieved earlier in the group's development, then members are likely to experience benefits from the group in a shorter amount of time.

This paper's conclusions suggest that clinicians interested in conducting HIV/AIDS support groups are encouraged to select people who are in the same stage of HIV/AIDS illness, share the same risk groups, and are the same gender. Homogeneous groups would be the ideal group composition, in which the curative factors would be facilitated. It is recognized that practical considerations often dictate that groups be composed of members that are heterogeneous on these variables. Clearly, there are advantages of homogeneous groups, but if this is not an option for people with HIV or PWAs, then it would be important for groups to be composed of a balance in membership. To decrease this population's sense of isolation, group composition should provide members with people similar to themselves.

Changes over time in the physical status of group members presents a concern for practitioners in conducting treatment with this population. For example, if a group member from a HIV-positive, asymptomatic group begins to develop symptoms, does he or she have to then leave the group? And what are the effects of leaving the group? One solution to this problem could be to initially have short-term, closed groups for people with asymptomatic HIV. GMHC in New York found that people often attend drop-in groups, and then move to a closed-membership group, designed for a longterm commitment (Gambe and Getzel, 1989). Perhaps time-limited, homogeneous groups for people who are HIV-positive, asymptomatic could be followed by long-term groups for people who have begun to develop symptoms of AIDS.

Finally, while clinical wisdom developed through extensive and relevant experience is helpful to practitioners, empirical validation of clinical impressions must take place. Translating the patient's perceptual experience of therapy into measurable and manipulatable variables is always 
challenging. Yalom (1985) himself notes that there is "little truly definitive research demonstrating the efficacy of any of the therapeutic factors ..." given the subjectivity and complexity of the group experience. Nevertheless, preliminary work can be devoted to operationalizing such factors as universality and instillation of hope as measurable objective phenomena. Yalom and his colleagues (Yalom et al., 1968) employed a Q-sort technique utilizing items written by clinicians to describe each factor. Homogeneous and heterogeneous groups would be compared on each relevant dimension (i.e. stage of illness) of group composition utilizing the operationalized curative factor constructs as outcome measures. However preliminary such efforts may be, establishing an empirical foundation for clinical decisions around group composition should be a priority for those committed to the effective treatment of the HIV patient.

\section{REFERENCES}

Beckett, A., and Rutan, J. S. (1990). Treating persons with ARC and AIDS in group psychotherapy. Int. J. Group Psychother. 40: 19-29.

Beckham, D. (1988). Group work with people who have AIDS. J. Psychosocial Oncol. 6: 213-218.

Bieber, T. (1974). Group and individual psychotherapy with male homosexuals. Group and Individual Psychother. Male Homosex. 2: 255-260.

Bing, E. G., and Soto, T. A. (1991). Treatment issues for African-Americans and Hispanics with AIDS. Psychiatric Med. 9: 455-467.

Brauer, S. (1990). The infected individual: Group work as a rite of passage. Smith College Studies Social Work 60: 233-243.

Center for Disease Control and Prevention. (1993). HIVIAIDS Surv. Rep. 5: 1-19.

Child, R., and Getzel, G. S. (1989). Group work with inner city persons with AIDS. Social Work Groups 12: 65-80.

Christ, G. H., Wiener, L. S., and Moynihan, R. T. (1986). Psychosocial issues in AIDS. Psychiatric Ann. 16: 173-179.

Chung, J. Y., and Magraw, M. M. (1992). A group approach to psychosocial issues faced by HIV-positive women. Hosp. Commun. Psychiatry 43: 891-894.

Coates, T. J., Stall, R., Mandel, J. S., Boccellari, A., Sorensen, J. L., Morales, E. F., Morin, S. F., Wiley, J. A., and Mckusic, L. (1987). AIDS: A psychosocial research agenda. Ann. Behav. Med. 9: 21-28.

Cochran, S. D., and Mays, V. M. (1991). Psychosocial HIV interventions in the second decade: A note on social support and social networks. Counsel. Psychol. 19: 551-557.

Coleman, V. E., and Harris, G. N. (1989). A support group for individuals recently testing HIV positive: A psycho-educational group model. J. Sex Res. 26: 539-548.

Davis, I. (1991). What drug treatment professionals need to know about medical aspects of HIV illness. In M. Shernoff (ed.), Counseling Chemically Dependent People With AIDS, Harrington Park Press, New York, pp. 17-30.

Duhatschek-Krause, A. L. (1989). A support group for patients and families facing life-threatening illness: Finding a solution to non-being. Social Work Groups 12: 55-69.

Fawzy, F. I., Fawzy, N. W., and Pasnau, R. O. (1991). A model of a psychiatric intervention for AIDS patients. Psychiatr. Med. 9: 409-422.

Fawzy, F. I., Namir, S., and Wolcott, D. L. (1989). Structured group intervention model for AIDS patients. Psychiatr. Med. 7: 35-45. 
Field, H. L., and Shore, M. (1992). Living and dying with AIDS: Report of a three-year psychotherapy group. Group 16: 156-164.

Flanzer, J. P., and April, F. A. (1977). A diagnostic-treatment model for effective group treatment of drug abusers. J. Psychedel. Drugs 9: 143-150.

Gambe, R., and Getzel, G. S. (1989). Group work with gay men with AIDS. Social Casework 70: $172-179$.

Getzel, G. (1991). Survival modes for people with AIDS in groups. Social Work 36: 7-11.

Getzel, G., and Mahony, K. (1990). Confronting human finitude: Group work with people with AIDS (PWAs). J. Gay Lesb. Psychother. 1: 105-120.

Grant, D. (1988). Support groups for youth with the AIDS virus. Int. J. Group Psychother. 38: $237-251$.

Grant, D., and Anns, M. (1988). Counseling AIDS antibody-positive clients: Reactions and treatment. Am. Psychol. 43: 72-74.

Green, J. (1989). Counseling for HIV infection and AIDS: The past and the future. Aids Care 1: 5-10.

Grief, G., and Price, C. (1988). A community-based support group for HIV positive I.V. drug abusers: The hero program. J. Subst. Abuse Treat. 5: 263-266.

Hedge, B., and Glover, L. F. (1990). Group intervention with HIV seropositive patients and their partners. AIDS Care 2: 147-154.

Hockings, J. (1989). AIDS counselling in the context of the Terrence Higgins Trust. Counselling Psychol. Quart. 2: 83-87.

Hoffman, M. (1991). Counseling the HIV-infected clients: A psychosocial model for assessment and intervention. Counseling Psychologist 19: 467-542.

Katoff, L., and Dunne, R. (1988). Supporting people with AIDS: The gay men's health crisis model. J. Pall. Care 4: 88-95.

Knapp, S., and Vande Creek, L. (1990). What Every Therapist Should Know About AIDS. Professional Resource Exchange, Inc., Sarasota, Florida.

Kurdek, L. A., and Siesky, G. (1990). The nature and correlates of psychological adjustment in gay men with AIDS-related conditions. J. Appl. Social Psychol. 20: 846-860.

Levine, S. H., Bystritsky, A., Baron, D., and Jones, L. D. (1991). Group psychotherapy for HIV-seropositive patients with major depression. Am. J. Psychother., 45: 413-424.

Levy, R. S., Tendler, C., Van Devanter, N., and Cleary, P. D. (1990). A group intervention model for individuals testing positive for HIV antibody. Am. J. Orthopsychiatry 60: 452-459.

Mancoske, R. J., and Lindhorst, T. (1991). Mutual assistance groups in a shelter for persons with AIDS. Social Work Groups 14: 75-86.

Morin, S. F., Charles, K. A., and Malyon, A. K. (1984). The psychological impact of AIDS on gay men. Am. Psychologist 39: 1288-1293.

Mulleady, G., Riccio, M., and Hogarth, S. (1989). HIV infection and drug users: Setting up support groups. Counsel. Psychol. Quart. 2: 53-57.

National Institutes of Health (1993). AIDS Research: An NIMH Blueprint for the Second Decade 1993-2003, 1-22.

Nichols, M. (1989). The forgotten seven percent: Women and AIDS. In C. D. Kain (ed.), No Longer Immune: $A$ Counselor's Guide to AIDS, American Association for Counseling and Development, Alexandria, VA, pp. 77-92.

Nichols, S. E. (1984). Social and support groups with patients with acquired immune deficiency syndrome. In S. E. Nichols and D. G. Ostrow (eds.), Psychiatric Implications of Acquired Immune Deficiency Syndrome, American Psychiatric Press, Washington, DC, pp. 77-82.

Nichols, S. E. (1983). Psychiatric aspects of AIDS. Psychosomatics 24: 1083-1089.

Nichols, S. E. (1986). Psychotherapy and AIDS. In T. S. Stein and C. J. Cohen (eds.), Contemporary Perspectives on Psychotherapy with Lesbians and Gay Men, Plenum Medical Book Company, New York, pp. 209-239.

O'Dowd, M. A., Natali, C., Orr, D., and McKegney, F. P. (1991). Characteristics of patients attending an HIV-related psychiatric clinic. Hosp. Commun. Psychiatry 42: 615-619.

Price, R. E., Omizo, M., and Hammett, V. L. (1986). Counseling clients with AIDS. J. Counsel. Devel. 65: 96-97. 
Rosenberg, P. P. (1984). Support groups: A special therapeutic entity. Small Group Behav. 15: 173-186.

Ross, M. W., and Rosser, B. S. (1988). Psychological issues in AIDS-related syndromes. Patient Ed. Counsel. 11: 17-28.

Sageman, S. (1989). Group therapy for patients with AIDS. In D. A. Halperin (ed.), Group Psychodynamics: New Paradigms and New Perspectives, Year Book, Chicago, pp. 125-138.

Schwartz, R. D., and Hartstein, N. B. (1986). Group psychotherapy with gay men. In T. S. Stein and C. J. Cohen (eds.), Contemporary Pespectives on Psychotherapy with Lesbians and Gay Men, Plenum Medical Book Company, New York, pp. 157-177.

Simerly, R. T., and Karakashian, S. J. (1989). Psychotherapy with HIV-positive, ARC, and AIDS patients: Clinical issues and practice management. Trans. Anal. J. 19: 176-185.

Smeltzer, S. C., and Whipple, B. (1991). Women and HIV infection. IMAGE J. Nurs. Scholar. 23: $249-256$.

Spector, I. C., and Conklin, R. (1987). AIDS group psychotherapy. Int. J. Group Psychother. 37: 433-439.

St. John, M. (1992). Anti-body already: Body-oriented interventions in clinical work with HIV-positive women. Wom. Ther. 13: 5-25.

Taylor, J. R., and Strassberg, D. S. (1986). The effects of sex composition on cohesiveness and interpersonal learning in short-term personal growth groups. Psychotherapy 23: 267-273.

Thompson, E. H., and Wardrope, D. (1988). An AIDS/ARC support group in a correctional institution: General and specific considerations. $J$. Prison Jail Health 7: 59-75.

Tross, S., and Hirsch, D. A. (1988). Psychological distress and neuropsychological complications of HIV infection and AIDS. Am. Psychol. 43: 929-934.

Tunnell, G. (1991). Complications in group psychotherapy with AIDS patients. Int. J. Group Psychother. 41: 481-498.

Weiss, R. S. (1988). The experience of AIDS: Hypotheses based on pilot study interviews. J. Pall. Care 4: 15-25.

Wiener, L. S. (1991). Women and human immunodeficiency virus: A historical and personal perspective. Social Work 36: 375-378.

Wolcott, D. L., Fawzy, F. I., Landsverk, J., and McCombs, M. (1986). AIDS patients' needs for psychosocial services and their use of community service organizations. J. Psychosocial Oncol. 4: 135-145.

Wolcott, D. L., Fawzy, F. I., and Pasnau, R. O. (1985). Acquired immune deficiency syndrome (AIDS) and consultation-liaison psychiatry. Gen. Hosp. Psychiatry 7; 280-292.

Yalom, I., Tinklenberg, J., and Gilula, M. (1968). Curative factors in group therapy. Unpublished study. In I. D. Yalom (ed.) (1985). The Theory and Practice of Group Psychotherapy (third edition), Basic Books, New York.

Yalom, I. D. (1985). The Theory and Practice of Group Psychotherapy (third edition), Basic Books, New York.

Zakrzewski, P. A. (1991). Short term group work with intravenous drug using people with AIDS in a hospital setting. J. Chem. Depend. Treat. 4: 55-65. 